\title{
The supply of public goods in rural community
}

\author{
Haijian Li \\ Zhengzhou College of Animal Husbandry Engineering \\ Zhengzhou, China \\ lihaijian671@sohu.com
}

\begin{abstract}
The rural community is the most basic of community organizations, but also the production and living community. Rural community public goods supply situation to the production and the quality of life and the harmony of the community, the rural public product of the community to provide it with different characteristics of city community. More community provision of public goods is the collective behavior of the results. This paper based on the collective behavior perspective, analysis of rural public product of the community to provide farmers always face the risk aversion, hitchhiking and other opportunistic behavior of temptation. This paper puts forward the countermeasures to improve the community level of the supply of public goods.
\end{abstract}

Keywords- rural communities; public goods; local rules

\section{INTRODUCTION}

In recent years, scholars from different angles were studied and discussed the countryside public product to the farmer production lives the role. They generally agree the rural public goods is not only the rural economic and social functioning and development foundation, is also the overall urban and rural development, building a new socialist countryside is the inevitable requirement of. But there are more scholars on the current rural public goods supply problems are summarized. These drawbacks showed in short supply, structural unbalance and low efficiency problems. They are also from the improved view angle put forward different countermeasure train of thought. All these have laid a foundation for further research. In the construction of new socialist countryside, the construction of a harmonious society and promoting rural "community" construction process, let a farmer to live a decent life background, on the supply of rural public goods have put forward higher requirements. The rural community is the most grass-roots community, the public product supply situation how, direct relation with community villager production quality of life, related to community harmony and stability. This article from the perspective of collective behavior comprehensive review of rural community public goods characteristics, rural communities and particularity of community collective behavior improvement on the existing research results in the foundation, proposed the improvement of rural community public goods supply may be thought.

\section{RURAL COMMUNITY PUBLIC GOODS CHARACTERISTICS}

Public goods and private goods is an opposite concept. It means that every person the consumption of this product does not cause others to the product consumption reduction. Public products have two basic characteristics of non exclusiveness and blame emulative. Rural public product of the community is in the rural communities of the area within the scope of rural resident's consumption, common public product. Its supply to rural community as the unit, according to the residents of the community's changing needs, the government, community or social group differences, much channel to supply.

In the content, the public goods in rural communities including and farmer's production and life are closely related within the community of road, water, electricity, communications, education, employment and training, science and technology services, health care, social security, water project, town planning, cultural and sports entertainment facilities and system at the level of village regulations and public facilities in rural communities, public utilities, public service, public welfare and other aspects of public products. These kinds of rural community public goods for the community residents of production, life and development play a very important role.

Rural community public goods are a branch of public products. It has two basic characteristics of public products. But in view of the borderline and production of rural communities, rural community public goods have its unique characteristics of urban community public products. The first more has the nature of quasi-public goods. Rural community public goods supplied by the government, except for a handful of pure public products, mostly have some degree of competition or exclusive of quasi public goods. In second, rural community public goods have greater positive externality. Rural community public product supply to the increase of farmers' income, the expansion of consumption and promoting employment, stimulating effect is obvious; In third, have stronger homogeneity. Rural communities within the income level of the dweller, consumption level, folk custom, religious belief etc the difference is relatively small, homogeneous demand; fourth, has the advantages of high level of. Since reforming and opening, the development of the rural community level has increased significantly, income level of the dweller, consumption level and civilization degree is improved. In the basic satisfy the needs of living and production of the public product supply base, in 
the pursuit of higher development and higher degree of civilization, in the community public products supply levels are rising demand desire. In fifth, there is the cost of precipitation. Rural community except a portion of quasi public products can be charged through the back part of the cost, quite one part cost to form a precipitate, cannot recover.

\section{COMMUNITY PROVISION OF PUBLIC GOODS ON THE COLLECTIVE BEHAVIOR}

\section{A. The characteristics of rural communities}

For the rural community, it is generally accepted that the concept is a village community. The author thinks to basically have the following characteristics: first, the production life of the geopolitical nature. The village community in general is in the specific region. Not only agricultural production and living with regional, and relations between people has obvious geographical color; second, live dispersive, occupation differentiation degree is relatively low. People living in a certain region, population density is relatively low urbanization, mobility is relatively small, residents' occupation low degree of differentiation, mainly to farmers; in third, the production life of a high degree of dependence on nature. Agricultural production and farmer's land and natural resources allocation process. Fixed relative to the area of residence, the residents decided to natural dependence degree; fourth, occupy an important position in the family in the community. In the community the initial stage of development, the family is not only the center of economic activity, but also social, educational and entertainment center; fifth, the interpersonal relationship of simple. Kinship and neighborhood relationship is the main human relations. Daily life and production to interact, mutual help, feeling increasingly close together, formed gradually help one another in defense work, live together in groups.

\section{B. rural community public goods provision of collective behavior}

Public choice theory in Hardin's "the tragedy of the commons", generally use the "prisoner's dilemma" and Olsen's "the logic of collective action" theoretical model are illustrated by the people in the provision of public goods, always face lift, evading responsibilities or other opportunistic behavior of temptation. There is no momentum for the collective interests to make contribution, but will only choose to do a hitchhiker. If all the people choose to ride, won't produce collective interests. Even though some people to provide public products (collective products) and another part person hitchhiking, will lead to the interests of the collective supply is not up to the optimal level.

Rural couplet is produced contract after system of job responsibility, because the traditional centralization of state power or authority was extremely challenging situations, rural residents based on "rational person" thinking, and more willing to make a hitchhiker. As for the rural traditional "help one another in defense work" the erosion of traditional, Five-guarantee pension problem has become a big problem.
In the production and living facilities also appeared of different level of cooperation, so that the collective interests and social interests generally impaired. Their performance in cannot be effectively organized public infrastructure construction and public facilities construction, rural community environment filthy phenomenon no one shows any interest in such phenomena. This because of individual reason collective irrationality, the pursuit of individual selfinterest leads to collective interests, contrary to new rural construction of socialism and harmonious society development.

\section{COLLECTIVE BEHAVIOR TO IMPROVE THE INTERESTS OF THE COLLECTIVE AND IMPROVE}

The "tragedy of the commons", "prisoner's dilemma" and "the logic of collective action", a central problem is the freerider problem. If a person is not excluded by others to share the benefits, this man has to share common interests do contribute to the drive; it may choose to do a hitchhiker. The theoretical model is based on certain assumptions, such as the "prisoner's dilemma" in game two prisoners for potential strategies -- Frank is built on two prisoners were held, without mutual communication of information under the conditions of the individual rational choice. But if changing collective game variables, particularly changes in the analysis of the prisoner's dilemma in constraint conditions, such as in the next round of the game before they enter into a binding contract, provide sufficient and reliable information, and strengthen the enforcement of supervision, can reduce opportunistic behavior, promote and encourage individuals to the collective interest make a contribution.

The famous American administrative experts, political economist Eleanor Storm for small-scale communal pond system how to carry out effective management puts forward: "a group of dependent clients how to organize themselves, for independence, which in all face lift, evading responsibilities or other opportunistic behavior temptation situations, made of a durable common interest, must also address the question of how the variables to be combined, so that: (1) increased autonomy organization initial possibility; (2) to enhance the people continuously independent organization ability; (3) enhanced without some external assistance situation through independent organization to solve problems the ability of public resources.

To solve the current rural public product of the community to provide problems, Professor Eleanor Edstrom's treatment plan is very significance. The author thinks, should first cultivate rural community elite. In the village the democratic election, should be on the system guarantee of the election process in fairness, justice, public. The election result can truly reflect the will of the villagers. True love the cause of public welfare, entrepreneur spirit and sense of community can be elected. And its modern agriculture, modern public management knowledge training to play them in community construction, especially in the provision of public goods in the organizer and coordinator of the role.

At present throughout the country on the every kind of village cadre training, although obtained not small result, but 
also appeared unrealistic, formalistic malpractice content. Therefore, in village cadre training, in the training content and form of Kung $\mathrm{Fu}$, improve the pertinence and effectiveness of training. In second, the community public products provision should fully reflect the village, villagers preferences display channel unobstructed. Since reforming and opening, in the country carried out a variety of standard upgrade. Due to the top-down decision, did not take into account the actual, offers many "face job" does not suit the demand of the farmer, play the role of minimal. But due to lack of the corresponding management after the completion of the project, spend a great deal of manpower and financial resources, damage alarming. The farmers agree with these great views.

To a certain extent, contused the farmer is contributive give work to provide public products actively. But there are many places in the community construction; exploration gives out of "prisoner's dilemma" new approach. Such as the Henan province Dengzhou city at village level organization construction and democratic management practice, the creation of the "4+2" working method. Due to the significant matters villagers have knowledge right, right of participation and decision making authority, villagers Shun gas, to participate in the enthusiasm is all-time and rising. At the same time also solve many difficult problems to be solved in the past. Third, strengthen the construction of community of village regulations. Village compasses civilian construction is the community system construction, but also the important content of socialist cultural construction in rural areas. It is easy to be accepted by people form, with rural excellent tradition and reflect socialism new rural construction as the content, is the behavior standard. In rural communities, the "acquaintance society", village regulations to play both normative village daily behavior, and stimulate the villagers in the community recognition, lead to the formation of collective behavior ability. Fourth, implement the full information disclosure system. The village has a completely symmetrical information, can reduce the decision-making and supervision cost, village for which involves the community public products in the construction and operation, can do well, can gradually develop citizen and civic responsibility, is to stimulate the villagers' participation in community building foundation.

\section{REFERENCES}

[1] Eleanor Ostrom. Public Affairs Governance: the evolution of institutions for collective action [M]. Shanghai Sanlian bookstore in 2000 June.

[2] Mancer Olsen. The logic of collective action [M]. Shanghai Sanlian bookstore in 2008 April.

[3] Liu Zhaorui. Active exploration party organization under the leadership of the new mechanism of villagers' Autonomy -- the Henan province Dengzhou city is carried out "4+2" working method "the investigation and thinking [J]. Academic Journal of Zhongzhou ,2009,6: 17〜20.

[4] Samulson, P.A. 1954. The Pure Theory of Public Expenditure. The Review of Economics and Statitics[J]. Volume 36. Issue 4. 387 389 .

[5] Paul W Barkley, 1974. "Public Goods in Rural Areas: Problems, Policies, and Population " ,American Journal of Agricultural Economics[J]. 56(5): 1135 1142. 